\title{
Accuracy of death certificate diagnosis of amyotrophic lateral sclerosis
}

\author{
Adriano Chiò, Corrado Magnani, Enrico Oddenino, Gianpiero Tolardo, David Schiffer
}

\begin{abstract}
Study objective-The aim was to determine the reliability of official mortality statistics in estimating long term trends of amyotrophic lateral sclerosis (ALS) in Italy.

Design-The study was a mortality follow up of cases of ALS.

Setting-Piedmond Region, northern Italy.

Subjects-Cases of ALS were identified from multiple sources between 1966 and 1985.

Main results-Cause of death was determined for the cases who died between 1970 and 1985. Death certificates were obtained in 488 out of 510 cases $(95 \cdot 7 \%)$. ALS was mentioned in $365(\mathbf{7 4 . 8 \% )}$ ) of cases. The most frequent erroneous diagnoses were multiple sclerosis and malignant tumours. Demographic variables, such as sex, age at death, province of death, and calendar year of death, did not influence the percentage of true positive cases significantly.

Conclusions-The death certificate diagnosis of ALS appears to be adequate for use in descriptive and analytical epidemiology. $f$ Epidemiol Community Health 1992; 46: 517-518
\end{abstract}

Recent reports have suggested notable increase in mortality rates of amyotrophic lateral sclerosis (ALS) in some countries (United States, France, Sweden). ${ }^{1-3}$ However, epidemiological studies of ALS based primarily on the analysis of death certificate data have several limitations, ${ }^{1} 24$ mainly due to the questionable accuracy of reporting the diagnosis of ALS in death certificates. On the other hand, mortality statistics represent a unique source of data for epidemiological surveys over a long period and on large populations.

This study was designed to determine the reliability of mortality statistics in estimating long term trends of ALS mortality in Italy.

Il Department of Neurology, University of Turin, Ospedale Molinette, 10126 Torino, Via Cherasco 15 , Italy A Chio

E Oddenino

G Tolardo

D Schiffer

Cancer Epidemiology

Unit, University of

Turin, Turin, Italy

C Magnani

Correspondence to:

Dr Chio Accepted for publication
March 1992

\section{Methods}

This study of validity of death certificate diagnosis of ALS uses the data of a previous population based survey of ALS incidence rates trend in Piedmont Region, northern Italy, ${ }^{5}$ in the period 1966 to the end of 1985. All cases deceased during the period 1970-1985 were considered. The cases were collected from different sources: (a) the archives of the neurological and geriatric departments of the region; (b) the central computerised discharge archive of the Piedmont Region; (c) the and Aosta Region, where all death certificates of residents in the region are stored; (d) the archives of electromyography laboratories of the region; (e) the social security records; ( $f$ ) the files of the consultant neurologists practising in the area. Patients were included in the study if a definite clinical diagnosis of ALS was made, following strict diagnostic criteria. ${ }^{6}$ Death certificates were obtained from the vital statistics bureau in the community in which each patient died. Because in most cases contributory causes of death could not be obtained, only primary causes were used for calculations. Statistical analyses are limited to the computation of the proportion of death certificates correctly reporting ALS as the underlying cause of death. The significance of the trend of death certificate diagnosis by age groups was tested by means of the Armitage method. ${ }^{7}$

\section{Results}

In the area examined, a total of 510 cases of ALS died during the period 1970 to $1985-315$ males and 195 females (sex ratio: 1.61:1). The mean age at death was 61.5 (SD 12.4) years.

Death certificates were obtained in 488 cases $(95.7 \%)$. ALS was indicated as primary cause of death in 365 cases $(74.8 \%$ true positive rate). In table I the most frequent other diagnoses are shown. Of the death certificates where a different diagnosis appeared, multiple sclerosis and malignant tumours were the most frequently indicated.

No significant difference in the frequency of ALS diagnosis in death certificates was found when various factors were considered (sex, age at death, province of death, period of death) (tables II-V). The proportion of true positive cases showed a decreasing trend with age at death $\left(\chi^{2}\right.$ for trend, $p<0.05$ ). The true positive rate did not vary significantly according to year at death: the figures were $77 \%$ in $1970-1974,73 \%$ in $1975-$ 1979 , and $75 \%$ in $1980-1985$. archives of the tumour registry for the Piedmont

\section{Discussion}

The use of official mortality statistics for descriptive epidemiological studies may have several biases, the main one being the accuracy of death certificates reporting a disease. It is therefore important to define the reliability of death certification of ALS, in particular to determine whether there are geographical, temporal, and demographic variations in ALS reporting, in order to define whether mortality data can be used for epidemiological analysis.

Few studies have analysed the accuracy of death certificates of ALS: two population studies, from 
Table I Causes of death listed on death certificates of patients with a clinical diagnosis of amyotrophic lateral sclerosis

\begin{tabular}{lcc}
\hline & Number & Percent \\
\hline Amyotrophic lateral sclerosis & 365 & $74 \cdot 8$ \\
Multiple sclerosis & 23 & $4 \cdot 7$ \\
Malignant tumours and leukaemias & 22 & $4 \cdot 5$ \\
Acute myocardial infarction and heart faliure & 18 & $3 \cdot 7$ \\
Pneumonia, respiratory failure & 14 & $2 \cdot 9$ \\
Muscular dystrophy & 10 & $2 \cdot 0$ \\
Progressive palsy & 7 & $1 \cdot 4$ \\
Cerebral haemorrage and stroke & 6 & $1 \cdot 2$ \\
Cerebral arteriosclerosis & 6 & $1 \cdot 2$ \\
Muscular atrophy & 4 & $0 \cdot 8$ \\
Myasthenia gravis & 3 & $0 \cdot 6$ \\
Trauma & 3 & $0 \cdot 6$ \\
Polyneuritis & 2 & $0 \cdot 4$ \\
Other causes & 2 & $1 \cdot 0$ \\
All cases & 488 &
\end{tabular}

Table II Death certificate diagnosis by sex

Table III Death certificate diagnosis by age groups at death

\begin{tabular}{lccl}
\hline & ALS & $\begin{array}{l}\text { Other } \\
\text { causes }\end{array}$ & $\begin{array}{l}\text { All } \\
\text { cases }\end{array}$ \\
\hline Males & $221(73 \cdot 4 \%)$ & $144(26 \cdot 6 \%)$ & 365 \\
Females & $80(77 \cdot 0 \%)$ & $43(23 \cdot 0 \%)$ & 123 \\
All cases & 301 & 187 & 488 \\
\hline
\end{tabular}

\begin{tabular}{lllr}
\hline Age (years) & ALS & $\begin{array}{l}\text { Other } \\
\text { causes }\end{array}$ & $\begin{array}{l}\text { All } \\
\text { cases }\end{array}$ \\
\hline$\leqslant 44$ & $33(82 \cdot 5 \%)$ & $7(17.5 \%)$ & 40 \\
$45-59$ & $110(77 \cdot 5 \%)$ & $32(22.5 \%)$ & 142 \\
$60-74$ & $188(74.3 \%)$ & $65(25.7 \%)$ & 253 \\
$\geqslant 75$ & $34(64 \cdot 2 \%)$ & $19(35 \cdot 8 \%)$ & 53 \\
All cases & 365 & 123 & 488 \\
\hline$\chi^{2}=4 \cdot 62.0<00.05$ & &
\end{tabular}

Japan and Finland, ${ }^{89}$ found that $4-8 \%$ of ALS cases were classified as non-ALS, and that $6 \%$ of ALS certificates were not ALS cases. Unfortunately, in both studies, the investigators examined the certificates over a short time period and did not analyse geographical and demographic variations. Other studies, based on cases discharged by a single centre or by a group of hospitals, ${ }^{10-12}$ found a higher false positive rate, varying from 10 to $28 \%$.

The present study, which is the first of this type to be performed in Italy, is based on all cases clinically diagnosed as ALS who died in Piedmont region between 1970 and 1984 . The large number of cases included in the study and the long period considered allowed us to analyse whether the accuracy of death certificates changed over time, in different socioeconomic areas, and in various age groups. Moreover, in this analysis, the cases were collected from many sources, such as EMG laboratories and consultant neurologists' archives, and not only from referral centres; this sample can be therefore considered a reliable and comprehensive representation of the whole ALS population and a true estimate of the ability of

Table IV Death certificate diagnosis by province of death

\begin{tabular}{lrrr}
\hline Area & \multicolumn{1}{c}{ ALS } & \multicolumn{1}{l}{$\begin{array}{l}\text { Other } \\
\text { causes }\end{array}$} & \multicolumn{1}{c}{$\begin{array}{l}\text { All } \\
\text { cases }\end{array}$} \\
\hline Town of Turin & $134(74 \cdot 4 \%)$ & $46(25 \cdot 6 \%)$ & 180 \\
Province of Turin & $97(76 \cdot 4 \%)$ & $30(23.6 \%)$ & 127 \\
Province of Vercelli & $31(73.8 \%)$ & $11(26 \cdot 2 \%)$ & 42 \\
Province of Cuneo & $69(80 \cdot 2 \%)$ & $17(19.8 \%)$ & 86 \\
Province of Asti & $25(64 \cdot 1 \%)$ & $14(35.9 \%)$ & 39 \\
Not deceased in Piedmont & $9(64 \cdot 3 \%)$ & $5(35 \cdot 7 \%)$ & 14 \\
All cases & $365(74 \cdot 8 \%)$ & $123(25 \cdot 2 \%)$ & 488 \\
\hline
\end{tabular}

death certificate data to reflect the epidemiology of ALS. The study was made in a single Italian region, but there is no reason to think that its findings cannot be extended to the whole country.

Our study found an evident underreporting of ALS as primary cause of death. Two different types of bias can be considered: (1) in approximately $15 \%$ of cases ALS was not mentioned because death was attributed to intercurrent diseases (ie, myocardial infarction, heart failure, pneumonia, respiratory failure, malignancies) occurring during the course of ALS; in this respect our data include only the underlying cause of death and we do not know the proportion of cases

Table V Death certificate diagnosis by period of death

\begin{tabular}{llll}
\hline & ALS & $\begin{array}{l}\text { Other } \\
\text { causes }\end{array}$ & $\begin{array}{l}\text { All } \\
\text { cases }\end{array}$ \\
\hline $1970-74$ & $94\left(77 \cdot 0^{\circ}{ }^{\circ}\right)$ & $28\left(23 \cdot 0^{\circ}{ }^{\circ}\right)$ & 122 \\
$1975-79$ & $115\left(73 \cdot 2^{\circ}\right)$ & $42\left(26 \cdot 8^{\circ}\right)$ & 157 \\
$1980-85$ & $156\left(74 \cdot 6^{\circ}{ }^{\circ}\right)$ & $53\left(25 \cdot 4^{\circ}{ }_{\circ}^{\circ}\right)$ & 209 \\
All cases & 365 & 123 & 488
\end{tabular}

for which ALS was listed as a contributory cause; (2) in $10 \%$ of cases true erroneous diagnoses were found, similar to those observed by other authors $^{910}$ (multiple sclerosis, muscular dystrophy, progressive palsy). These errors probably indicate a lack of familiarity on the part of general physicians with ALS and a greater awareness of other diseases.

Nevertheless, the result of our analysis is encouraging. The true positive rate is in line with most reports in other countries, taking into account that in the present survey we could not use the certification of ALS as a secondary cause of death. Moreover, no significant changes over time and in different geographical areas were found. Therefore, the death certificate diagnosis of ALS appears to be sufficiently accurate for use in descriptive and analytical epidemiology.

1 Lilienfeld DE, Chan E, Ehland J, et al. Rising mortality from motor neuron disease in the USA, 1962-1984. Lancet 1989; i: $710-13$.

2 Durrelmann $S$, Alperovitch A. Increasing trend of ALS in France and elsewhere: are the changes real? Neurology France and elsew

3 Gunnarsson L-G, Lindberg G, Söderfeld B, Axelson O.

The mortality of motor neuron disease in Sweden. Arch The mortality of motor

4 Alderson M. An introduction to epidemiology. London: Macmillan, 1976

5 Chiò A, Tribolo A, Oddenino E, Schiffer D. A crosssectional and cohort study of motor neurone disease in Piedmont, Italy. In: Clifford Rose F, ed. New evidence in $M N D / A L S$ research. London: Smith-Gordon and $\mathrm{Co}$ 1991: 49-52.

6 Mortara P, Chiò A, Rosso MG, Leone M, Schiffer D. Motor neuron disease in the province of Turin, Italy, 1966-1980. Survival analysis in an unselected population. 7 Neurol $S c i$ 1984; 66: 165-73.

7 Armitage P. Tests for linear trends in proportion and frequencies. Biometrics 1955; 11: 375-86.

8 Kondo K, Tsubaki T. Changing mortality patterns of motor neuron disease in Japan. F Neurol Sci 1977; 32: 411-24.

9 Jokelainen $M$. Amyotrophic lateral sclerosis in Finland. I: an Jokelainen M. Amyotrophic lateral sclerosis in Finland. I: an
epidemiologic study. Acta Neurol Scand 1977; 56: 185-93. epidemiologic study. Acta Neurol Scand 1977; 56: $185-93$.
0 Hoffman PM, Brody JA. The reliability of death certificate Hoffman PM, Brody JA. The reliability of death certificate
reporting from amyotrophic lateral sclerosis. F Chron Dis
$1971 ; 24: 5-8$.

11 O'Malley F, Dean G, Elian M. Multiple sclerosis and motor neurone disease: survival and how certified after death. $\mathcal{F}$ Epidemiol Community Health 1987; 41: 14-17.

12 Buckly J, Warlow C, Smith P, Hilton-Jones D, Irvine S, Tew JR. Motor neuron disease in England and Wales, 1959-1979. F Neurol Neurosurg Psychiatry 1983; 46: 197205. 